\title{
Фізична активність з елементами скелелазіння як допоміжний засіб корекції розладів аутичного спектра у дітей
}

\author{
Галина Гурова, Тетяна Петровська, \\ Маргарита Кадієва
}

Національний університет фрізичного виховання і спорту України, Київ, Україна

Анотація. Статистичне зростання кількості осіб з розладами аутичного спектра формує підвищення інтересу до методів та способів корекції та адаптації таких дітей у суспільстві. Цікавою темою для науковців $є$ вивчення впливу фізичної активності на розвиток дітей 3 розладами аутичного спектра. В роботі вперше досліджено фізичну активність з елементами скелелазіння як допоміжний засіб корекції розладів аутичного спектра. Мета. Вплив скелелазіння на комунікативну та поведінкову ссери розвитку дітей. Методи. Теоретичний аналіз і узагальнення даних науково-методичної літератури та документальних матеріалів; психолого-педагогічне спостереження; педагогічний експеримент; опитування; методи математичної статистики. Результати. У ході дослідження виявлено підвищення показників формування таких навичок комунікативної поведінки, в балах: соціальної реакції у відповідь, вміння висловлювати прохання, соціальної поведінки, діалогових навичок. Показники вміння привертати увагу та ставити запитання не змінилися, дезадаптивної поведінки, такі як агресія, аутоагресія, переривання поточної активності та стереотипні прояви зменшилися майже вдвічі. За результатами проведеної роботи можемо зробити висновок, що фізична активність з елементами скелелазіння позитивно впливає на комунікативну та поведінкову сфери розвитку дітей з розладами аутичного спектра та може застосовуватися як допоміжний засіб у його корекції. Цей вид активності сприяє зниженню проявів стереотипної поведінки, агресії та аутоагресії за рахунок високого рівня концентрації на поточній діяльності.

Ключові слова: аутизм, стереотипна поведінка, комунікативні навички, фрізична активність, скелелазіння.

\section{Halyna Hurova, Tetiana Petrovska, Marharyta Kadiieva}

\section{PHYSICAL ACTIVITY WITH ELEMENTS OF CLIMBING AS AN AUXILIARY MEANS FOR CORRECTING AUTISM SPECTRUM DISORDERS IN CHILDREN}

Abstract. The statistical increase in the number of people with autism spectrum disorders creates an enhanced interest in methods and ways of correction and adaptation of such children in society. An interesting topic for scientists is to study the impact of physical activity on the development of children with autism spectrum disorders. In this work, physical activity with climbing elements as an aid to the correction of autism spectrum disorders was studied for the first time. Objective. Influence of climbing on the communicative and behavioral spheres of children development. Methods. Theoretical analysis and generalization of data of scientific and methodical literature and documentary materials; psychological and pedagogical observation; pedagogical experiment; questionnaire; methods of mathematical statistics. Results. The study revealed an increase in the formation of the following skills of communicative behavior (in points) social response, the ability to express requests, social behavior, dialogue skills. Indices of the ability to attract attention and ask questions have not changed, maladaptive behaviors such as aggression, autoaggression, interruption of current activity and stereotypical manifestations have almost halved. Based on the results of this work, we can conclude that physical activity with elements of climbing has a positive effect on the communicative and behavioral spheres of development of children with autism spectrum disorders and can be used as an aid in its correction. This type of activity helps to reduce the manifestations of stereotypical behavior, aggression and self-aggression due to the high level of concentration on current activity. Keywords: autism, stereotypical behavior, communication skills, physical activity, climbing.
Hurova H, Petrovska T, Kadiieva M. Physical activity with elements of climbing as an auxiliary means for correcting autism spectrum disorders in children. Theory and Methods of Physical education and sports. 2020; 3: 65-69

DOI: $10.32652 /$ tmfvs.2020.3.65-69
Гурова Г, Петровська Т, Кадієва М. Фізична активність з елементами скелелазіння як допоміжний засіб корекції розладів аутичного спектру у дітей. Теорія і методика фрізичного виховання і спорту. 2020; 3: 65-69 DOI: 10.32652/tmfvs.2020.3.65-69
Вступ. Актуальність обраної теми зумовлена статистичним зростанням кількості осіб з розладами аутичного спектра і підвищенням інтересу до методів та способів корекції та адаптації в суспільстві таких дітей. Ранні дослідження поширеності аутизму (Lotter, 1966) становили близько чотирьох осіб на 10000 людей, проте вони змінилися і станом на 2005 р. наводяться вже такі дані: 30-60 випадків на 10000 населення [2].

Аутизм є одним 3 важких порушень розвитку, який характеризується серйозними недоліками у фрормуванні соціальних і комунікативних навичок, а також проявами стереотипних інтересів і паттернів поведінки $[10,13]$.

Можливості соціалізації осіб 3 аутизмом визначаються багатьма факторами. Основним недоліком при аутизмі $є$ порушення спілкування дитини 3 оточуючим світом, що може проявлятись у дезадаптації, агресії, аутоагресії, стереотипіях, перериванні поточної діяльності тощо [3]. Саме тому в цьому дослідженні було зроблено акценти на вивчення комунікативної та поведінкової сфер дітей 3 розладами аутичного спектра.

Видатними вченими сучасності І. Павловим та М. Бернштейном доведено вплив рухової активності на всі системи організму і центральної нервової системи включно. О. Максимова вважає, що запропоновані М. Бернштейном рівні побудови рухів слід розглядати значно ширше, а саме, як рівні психічного функціонування, психічної реакції людського організму, побудови спілкування, емоцій та поведінки [16].

3 точки зору фізичного розвитку, скелелазіння - це аеробні фрізичні заняття, що складаються 3 серії технік розтягування, реалізація яких вимагає контролю над тілом та планування складних рухів [15]. Саме тому як варіант фрізичної активності було обрано саме цей вид рухової активності. 
Дитина з аутизмом не завжди розуміє вимоги батьків або тренера і не завжди їй вдається виконувати правильно завдання в групі $[1,6,7]$. 3аняття зі скелелазіння мають в основному індивідуальний характер, що дає можливість знайти підхід до кожної дитини, тобто сформулювати завдання зрозумілим чином (вербально чи невербально).

Мета дослідження - вивчити вплив скелелазіння як виду фрізичної активності на корекцію комунікативної та поведінкової сфер дітей з розладами аутичного спектра.

Методи дослідження. Педагогічне спостереження здійснювали згідно з методичними рекомендаціями «Розвиток комунікації у дітей з аутизмом» Інституту спеціальної педагогіки НАПН України [2] та використанням форм А. В. Хаустова [9]. Інтерв'ювання батьків здійснювали відповідно до рекомендацій НАН України [2], на базі методики А. В. Хаустова «Оцінка комунікативних навичок у дітей з розладами аутистичного спектра» та К. A. Quill, K. N. Bracken, M. E. Fair «Оцінка соціальних і комунікативних навичок для дітей 3 аутизмом» [18]. Дослідження проводили у спеціально облаштованому залі для занять скелелазінням «UP» в м. Києві з січня по червень $2018 p$.

Результати дослідження та їх обговорення. У дослідженні взяли участь 12 дітей 7-11 років. Варто зазначити, що анатомо-фрізіологічні характеристики цієї категорії дітей повністю відповідають характеристикам, притаманним дітям такого віку. Що стосується комунікативних навичок та дезадаптивної поведінки, то згідно з класифікацією О. С. Нікольської [5], що виділяє чотири основні моделі поведінки дітей з аутизмом, вісім дітей можна умовно віднести до другої групи, а чотирьох - до четвертої.

Протягом шести місяців діти з різною формою аутичних розладів займались на скеледромі «UP» (м. Київ) за загально прийнятою методикою:

- розминка - 25 \% усього заняття (близько 15 хв);

- основні вправи скелелазіння - $50 \%$ усього заняття (близько $30 \times \mathrm{B})$;

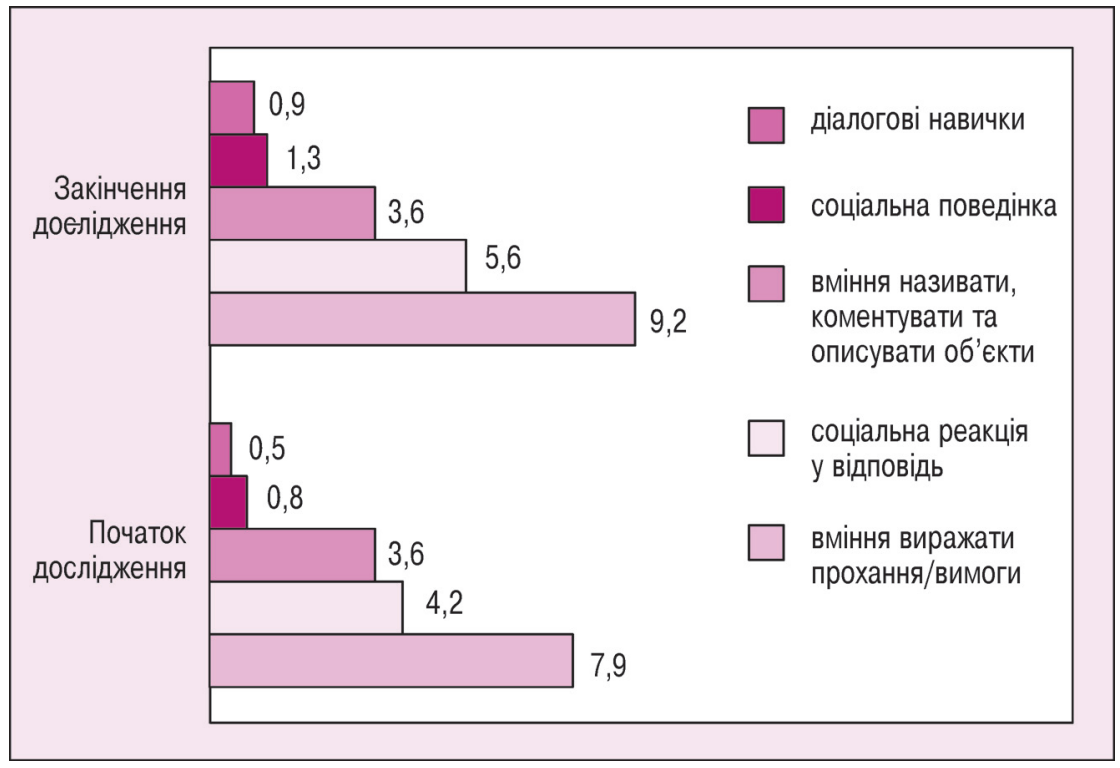

Рисунок 1 - Динаміка показників діалогових навичок за опитувальником А. В. Хаустова, бали

- заключна частина - 25 \% всього заняття (близько 15 хв).

Розминка складалась 3 аеробних вправ: стрибки і біг, вправи на розтягування та розігрів м'язів рук, ніг, спини, пальців, вправи для розвитку координації та балансування.

Основні вправи скелелазіння - лазіння вертикально вверх або вниз до вказаної точки, лазіння вбік (траверсом) до вказаної точки, виконання статичних вправ на зачіпках, лазіння по вказаному маршруту.

Заключна частина складалась із вправ на розтягування та зміцнення м'язів рук, ніг, спини та вправ загальної фрізичної підготовки.

Конкретні вправи підбирали для кожної дитини індивідуально залежно від рівня сприйняття інфрормації (здатність розуміти звернене мовлення) та здатності дитини до імітації рухів. У ході послідовно-порівняльного експерименту досліджували вплив оздоровчої рухової активності на динаміку показників комунікативних навичок та проявів дезадаптивної поведінки у дітей з розладами аутичного спектра.

На початковому та завершальному етапах було досліджено рівень сфрормованості комунікативних навичок у обстежуваних на основі опитувальника «Оцінка комунікативних навичок у дітей з розладами аутичного спектра» А. В. Хаустова [9], який було модифіковано відповідно до мети до- слідження. Опитування проводили за такими напрямами: вміння висловлювати прохання/вимоги, соціальної реакції у відповідь, вміння називати, коментувати та описувати об'єкти та дії, привертати увагу та ставити запитання, соціальної поведінки та діалогових навичок. Розрахунки здійснювали у балах за кожним учасником окремо, а також визначали середне арифметичне всього контингенту з кожної навички.

Порівняння результатів опитування на початку дослідження і після застосування заходів скелелазіння говорить про підвищення показників формування таких навичок комунікативної поведінки (у балах): соціальна реакція у відповідь - на 1,4, вміння висловлювати прохання - на 1,3, соціальна поведінка - на 0,5, діалогові навички - на 0,4. Показники вміння привертати увагу та ставити запитання не змінилися (рис. 1).

За період проведення експерименту більшість дітей почали частіше відгукуватися на власне ім'я, відмовлятися від запропонованого предмета або діяльності за допомогою слів чи жестів, відповідати на привітання інших людей, висловлювати погодження вербально чи невербально.

Двоє дітей, яких можна віднести до четвертої групи розладів за класифрікацією 0. С. Нікольської [5], почали ініціювати діалог з дітьми, які були 


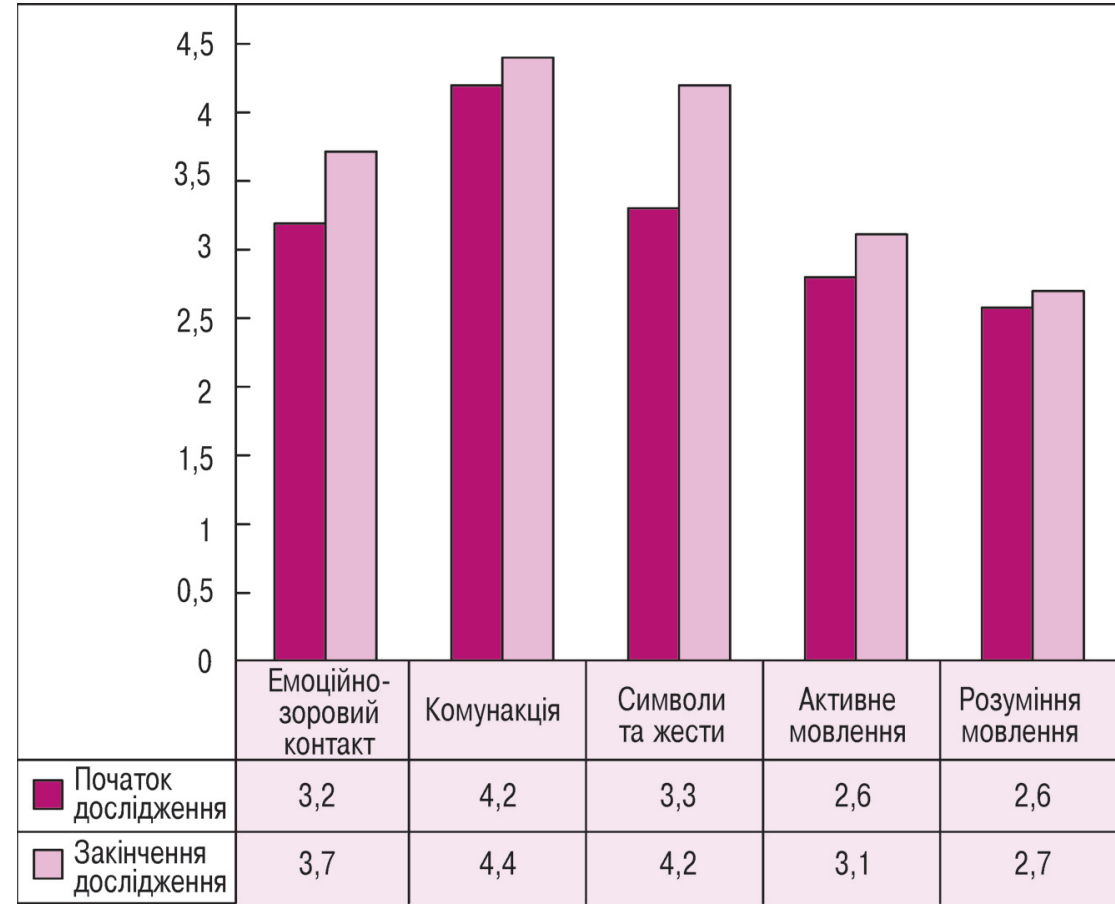

Рисунок 2 - Динаміка показників комунікативної сфери за результатами анкетування батьків, бал

присутні в залі під час тренувань, за допомогою таких стандартних фрраз: «Як тебе звати?», чи ставити запитання стосовно оточуючих «Хто це?».

Розрахунки за анкетами батьків здійснювали в балах по кожному учаснику експерименту окремо, та згідно 3 отриманими результатами розраховано середньоарифметичні дані з таких навичок: емоційно-зоровий контакт, комунікація, символи та жести, активне мовлення, розуміння мовлення.

Загалом батьки відмічають, що діти частіше використовують символи та жести у комунікативній поведінці (підвищення на 0,9 бала), демонструють емоційно-зоровий контакт (підвищення на 0,5 бала), тобто стежать за напрямком погляду батьків, коли їх просять принести чи знайти, або поглядають на них під час ігрової діяльності.

Показники комунікації та активного мовлення у середньому збільшилися на 0,3 бала, а показник розуміння мовлення - на 0,1 бала.

Динаміку показників за анкетою опитування батьків, розробленою за Методичними рекомендаціями IHституту спеціальної педагогіки НАПН України 2012 р. «Розвиток комунікації у дітей $з$ аутизмом» та представлено на рисунку 2.
Опитування батьків $є$ доцільним для аналізу комунікативних поведінкових проявів дитини та їх відповідності комунікативним фрункціям у різних ситуаціях і при взаємодії з різними людьми.

Для оцінювання динаміки проявів дезадаптивної поведінки було застосовано частину Протоколу педагогіч- ного обстеження А. В. Хаустова [9], де розрахунок результатів здійснювали за принципом - чим вищий бал, тим більший прояв небажаної поведінки і чим нижчий, тим таких проявів менше чи знизилася їх інтенсивність. На рисунку 3 наведено динаміку показників дезадаптивної поведінки на початку та наприкінці дослідження.

У більшості контингенту знизилися частота та інтенсивність проявів негативізму, а проміжки часу, коли діти концентрують увагу, подовжилися. Прояви імпульсивності, які виражаються в діях, що випереджають вказівку або хапання різних предметів, проявляються рідше або з меншою інтенсивністю.

Серед показників агресивної та аутоагресивної поведінки досліджувалися такі прояви, коли дитина кусає або щипає себе чи оточуючих, б'є, стукає себе по голові, плює на інших людей. У дітей, що належать до четвертої групи розладів аутичного спектра, прояви агресивної та аутоагресивної поведінки майже не спостерігаються, а от діти другої групи частіше мають деякі з цих проявів чи всі. У ході експерименту показники агресивної та аутоагресивної поведінки змінилися в середньому на 1 бал у бік зниження за рахунок того, що ця поведінка або стала менш інтенсивною або її частота знизилася.

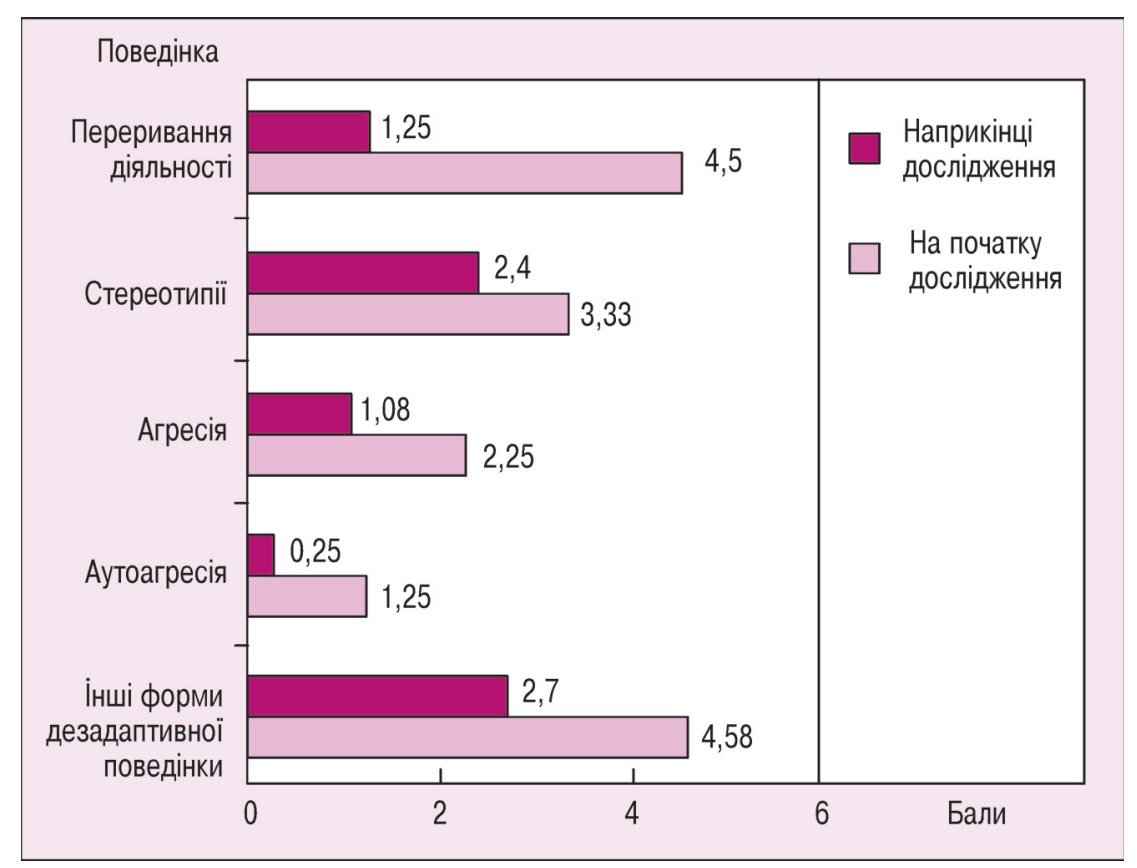

Рисунок 3 - Динаміка показників дезадаптивної поведінки, бал 
У дітей з розладами четвертої групи частіше спостерігалася стереотипічна поведінка у фрормі повторення певних слів чи фрраз, почутих раніше. В учасників дослідження з розладами другої групи, які переважно не користуються вербальними засобами комунікації та не вербалізуть щось більше, ніж буквосполучення, в основному спостерігається стереотипічна поведінка моторного характеру, така як трясіння чи махання руками. Спостереження під час занять за стереотипічною поведінкою дає можливість зробити висновки про те, що в цілому у більшості дітей, незалежно від групи розладів, зменшилася частота її проявів. Діти почали краще реагувати на вербальну вимогу про припинення такої поведінки.

Дискусія. У ході дослідження було отримано дані, які підтверджують результати Russell Lang та José Pedro Ferreira, a caмe, зниження показників проявів стереотипічної поведінки $[14,17]$. У цих дослідженнях було зроблено припущення, що стереотипічна поведінка знижується, тому що деякі вправи є схожими зі стереотипічними рухами, але ми маємо інші припущення.

Робота у вертикальному вимірі вимагає фрізичних здібностей, таких як сила, потужність і витривалість. Вона також вимагає розвитку таких навичок техніки, як рівновага й економність під час лазіння з майже нескінченою різноманітністю рухів, положень кутів нахилу. I найголовніше - властиве скелелазінню відчуття небезпеки вимагає ретельного контролю думок, уваги, тривог і страхів [12]. Тобто протягом заняття для стереотипій не залишається місця, а через деякий час після заняття вони повертаються, але 3 меншою частотою.

Скелелазіння як вид фрізичного навантаження залучає велику кількість м'язових груп, завдяки підвищенню споживання кисню, частоти серцевих скорочень, позитивно впливає на фрункції серцево-судинної та дихальної систем та активізує роботу центральної нервової системи. Як зазначають деякі учені, багаторазове сходження як простих так і помірних маршрутів скелелазіння активі- зує майже всі ділянки сенсомоторної системи [11], що цілком може сприяти позитивним змінам як у комунікативній, так і дезадаптивній поведінці дітей.

Важливим фрактором корекційного есректу є застосування принципів оперантної обумовленості [4, 8]. Оскільки скелелазіння дає дуже позитивний відгук у дітей, то майже не виникає необхідності у додатковій мотивації. Сама можливість виконати завдання на стенді $є$ мотивом для покращення поведінки і метою комунікації, хоча мінімальним її проявам.

У середньому динаміка показників комунікативної сфрери учасників контингенту, за спостереженнями в спортивному залі, має деякі відмінності від такої, яка відмічена батьками дітей, що скоріше пов'язано зі створенням тренером нагоди для спілкування в умовах спортивного залу, тоді як батьки часто не приділяють уваги створенню нагоди для спілкування [2].

Висновки. Оскільки прояви розладів аутичного спектра не бувають однаковими, то і відгук на корекцію в кожної дитини індивідуальний. Серед контингенту групи є діти, в комунікативній ссрері чи поведінці яких не відбулося жодних змін, і в той самий час одного із учасників одразу після закінчення експерименту було прийнято до дитячої секції зі скелелазіння, де він має можливість для розвитку навичок комунікації в середовищі однолітків та знаходиться в процесі інтеграції в суспільство.

Незважаючи на той фракт, що даний вид спорту $є$ індивідуальним, він сприяє інтеграції дитини у суспільство [16] і створює нагоду для дитини з розладами аутичного спектра мати хобі, яке позитивно впливає як на фрізичне здоров'я, так і сенсомотору активність м0зку [11]

Результати експерименту говорять про те, що такий вид оздоровчої рухової активності, як скелелазіння має позитивний вплив на прояви комунікативної та дезадаптивної поведінки і може виступати як засіб корекції розладів аутичного спектра [16] за умови, що дитині такий вид рухової активності подобається. Важливим фрактором успішності занять скелелазінням
3 корекційною метою виступає наявність у тренера базових знань у ссрері корекції розладів аутичного спектра, наприклад, таких типів терапевтичного втручання як TEACCH (Treatment and Education for Autistic and related Communication handicapped Children терапія і навчання аутичних дітей 3 комунікативними порушеннями) та прикладний аналіз поведінки (applied behavior analysis, $A B A$ ).

Конфлікт інтересів. Автори заявляють, що відсутній будь-який конфлікт інтересів.

\section{ЛITEРАТУРА}

1. Беттельхейм Б. Пустая крепость. Детский аутизм и рождение Я: Москва: Академический Проект; Фонд «Мир», 2013. 480 с.

2. Куценко ТО. Методичні рекомендації «Розвиток комунікації у дітей 3 аутизмом». Інститут спеціальної педагогіки НАПН України, УДК: $376-056.34: 616.896+376.064] \quad$ (072.2). 2012.

3. Лебединский ВВ, Никольская ОС, Баенская EP, Либлинг ММ. Эмоциональные нарушения в детском возрасте и их коррекция. Москва: Издательтво МГУ; 1990. 197 с.

4. Мухіна АЮ. Особливості використання прикладного аналізу в роботі з дітьми, які мають аутистичний спектр порушень. Вісник ЛНУ ім. Тараса Шевченка. 2018; 1 (315). УДК 159.922.76-056.313

5. Никольская ОС. Афффективная ссрера человека. Взгляд сквозь призму детского аутизма. Москва: Центр лечебной педагогики; 2000. $364 \mathrm{c}$.

6. Питерс Т. Аутизм: От теоретического понимания к педагогическому воздействию. Санкт-Петербург: Институт специальной педагогики и психологии; 1999. 192 с.

7. Скрипник ТВ. «Феноменологія аутизму» Монографія. Інститут спеціальної педагогіки НАПН України; Київ: Фенікс; 2010. 368 с.

8. Скіннер Б. Оперантна поведінка. Історія зарубіжної психології. Москва: МГУ, 1986. 66, 67.

9. Хаустов АВ, Красносельская ЕЛ, Хаустова ИМ. Дети с расстройствами аутистического спектра. Протокол педагогического обследования. Практика управления ДОУ. 2014;1: 32-50.

10. Cohen DJ \& Volkmar FR. (Eds.). (1997). Handbook of autism and pervasive developmental disorders (2nd ed.). John Wiley \& Sons Inc.

11. Daniel Cariusa, Lisa Hörniga, Patrick Ragertab, Elisabeth Kaminskiab (202 Characterizing cortical hemodynamic changes during climbing and its relation to climbing expertise. Neuroscience Letters, Volume 715, 10 January 2020, 134604.

12. 12. Eric J. Hörst, Training for Climbing: The Definitive Guide to Improving Your Performance (How To Climb Series), 3rd ed. Guilford: Falcon Guides, 2016. 352.13. Harris S.L. and J.S. Handleman (Eds) (2000) Preschool educational programs for Children with Autism (2-nd ed.). Austin, TX: Pro-Ed.

14. José Pedro Ferreira, Chrystiane Vasconcelos Andrade Toscano, Aristides Machado, Rodrigues, Guilherme Eustaquio Furtado, Mauro Gomes Barros, Rildo Souza Wanderley and Hum- 
berto Moreira Carvalho (2018). Effects of a Physical Exercise Program (PEP-Aut) on Autistic children's stereotyped Behavior, Metabolic and Physical Activity Profiles, Physical Fitness, and Health-related Quality of life: A study Protocol. Frontiers in Public Health, Volum 6, article 47. Published: 02 March 2018, doi: 10.3389/fpubh.2018.00047.

15. Orjana Velikonjaa, Katarina Čurića, Ana Ožurab Saša, Šega Jazbecb (2010) Influence of sports climbing and yoga on spasticity, cognitive function, mood and fatigue in patients with multiple sclerosis. Clinical Neurology and Neurosurgery Volume 112, Issue 7, September 2010 P. 597-601.

16. Petrovska Tetiana, Gurova Galyna. Correction of children with autism spectrum disorders communicative skills by means of specially organized motor activity. Educational space in the context of humanistic paradigm: the psychological priorities of modernity, dedicated to the creative heritage of I.0. Synytsa (November, 12, 2018).

17. Russell Lang, Lynn Kern Koegel, Kristen Ashbaugh, April Regester, Whitney Ence, Whitney Smith (2010). Physical exercise and individuals with autism spectrum disorders: A systematic review. Research in Autism Spectrum Disorders, 4 565-576.

18. Quill KA, Bracken KN, Fair ME, Fiore JA. Do-Watch-Listen-Say. Social and communication intervention for children with autism. Baltimore: Paul H. Brookes Publishing Co., 2002. 410.

\section{LITERATURE}

1. Bettelhaim B. Empty fortress. Children autism and birth: Moscow: Akademichesky proekt; Fond «Mir», 2013. $480 p$.

2. Kutsenko TO. Methodical recommendations «Development of communication in children with autism». Instytut spetsialnoi pedahohiky NAPN Ukrainy, UDK: 376-056.34:616.896+376.064] (072.2). 2012.

3. Lebedinsky VV, Nikolskaya OS, Baenskaya ER, Libling MM. Emotional disorders during childhood and their correction. Moscow: Izdatelstvo MGU; 1990. $197 \mathrm{p}$.

4. Mukhina Al. Features of using applied analysis with regard to children with autism spectrum disorders. Visnyk LNU im. Taras Shevchenko. 2018; 1 (315). UDK 159.922.76-056.313.

5. Nikolskaya OS. Human affective sphere. Looking through the prism of childhood autism. Moscow: Tsentr lechebnoy pedagogiki; 2000. 364 p.
6. Piters T Autism: from theoretical understanding to pedagogical impact. St. Petersburg: Institut spetsialnoy pedagogiki i psikhologiyi; 1999. $192 \mathrm{p}$.

7. Skrypnyk TV. «Autism phenomenology» Monograph. Instytut spetsialnoi pedahohiky NAPN Ukrainy; Kyiv: Feniks; 2010. 368 p.

8. Skinner B. Operant behaviour. History of foreign psychology. Moscow: MGU, 1986. 66, 67.

9. Khaustov AV, Krasnoselskaya EL, Khaustova IM. Children with autism spectrum disorders Pedagogical examination protocol. Praktika upravIeniya DOU Д0У. 2014;1: 32-50.

10. Cohen DJ \& Volkmar FR. (Eds.). (1997). Handbook of autism and pervasive developmental disorders (2nd ed.). John Wiley \& Sons Inc.

11. Daniel Cariusa, Lisa Hörniga, Patrick Ragertab, Elisabeth Kaminskiab (202 Characterizing cortical hemodynamic changes during climbing and its relation to climbing expertise. Neuroscience Letters, Volume 715, 10 January 2020, 134604.

12. 12. Eric J. Hörst, Training for Climbing: The Definitive Guide to Improving Your Performance (How To Climb Series), 3rd ed. Guilford: Falcon Guides, 2016. 352.

13. Harris S.L. and J.S. Handleman (Eds) (2000) Preschool educational programs for Children with Autism (2-nd ed.). Austin, TX: Pro-Ed.

14. José Pedro Ferreira, Chrystiane Vasconcelos Andrade Toscano, Aristides Machado Rodrigues, Guilherme Eustaquio Furtado, Mauro Gomes Barros, Rildo Souza Wanderley and Hum- berto Moreira Carvalho (2018). Effects of a Physical Exercise Program (PEP-Aut) on Autistic children's stereotyped Behavior, Metabolic and Physical Activity Profiles, Physical Fitness, and Health-related Quality of life: A study Protocol. Frontiers in Public Health, Volum 6, article 47. Published: 02 March 2018, doi: 10.3389/fpubh.2018.00047.

15. Orjana Velikonjaa, Katarina Čurića, Ana Ožurab Saša, Šega Jazbecb (2010) Influence of sports climbing and yoga on spasticity, cognitive function, mood and fatigue in patients with multiple sclerosis. Clinical Neurology and Neurosurgery Volume 112, Issue 7, September 2010. P. $597-601$.

16. Petrovska Tetiana, Gurova Galyna. Correction of children with autism spectrum disorders communicative skills by means of specially organized motor activity. Educational space in the context of humanistic paradigm: the psychological priorities of modernity, dedicated to the creative heritage of I.0. Synytsa (November, 12, 2018).

17. Russell Lang, Lynn Kern Koegel, Kristen Ashbaugh, April Regester, Whitney Ence, Whitney Smith (2010). Physical exercise and individuals with autism spectrum disorders: A systematic review. Research in Autism Spectrum Disorders, 4 $565-576$.

18. Quill KA, Bracken KN, Fair ME, Fiore JA. Do-Watch-Listen-Say. Social and communication intervention for children with autism. Baltimore: Paul H. Brookes Publishing Co., 2002. 410.

Надійшла 19.05.2020

\section{ІНФОРМАЦІЯ ПРО АВТОРІВ}

Гурова Галина Валеріївна ORCID 0000-0001-9756-5021, galyna.gurova@gmail.com Петровська Тетяна Валентинівна https://orcid.org/0000-0003-3936-1965, petrovska.tetiana@ gmail.com

Кадієва Маргарита Василівна ORCID 0000-0002-4837-1957, margokad@gmail.com

Національний університет фізичного виховання і спорту України, вул. Фізкультури 1, м. Київ, 03150, Україна

\section{INFORMATION ABOUT THE AUTHORS}

Gurova Galyna ORCID 0000-0001-9756-5021, galyna.gurova@gmail.com Petrovska Tetiana https://orcid.org/0000-0003-3936-1965, petrovska.tetiana@gmail.com Kadiyeva Margaryta ORCID 0000-0002-4837-1957, margokad@gmail.com

National University of Ukraine on Physical Education and Sport, 03150, Kyiv, Fizkul'tury str., 1. 